$\mathbb{T}$ periodica polytechnica

Civil Engineering

$54 / 1(2010) 23,30$

doi: 10.3311/pp.ci.2010-1.03

web: http://www.pp.bme.hu/ci

(c) Periodica Polytechnica 2010

RESEARCH ARTICLE

\section{Concrete strength tendency in the wall of cylindrical spun-cast concrete elements}

\author{
István Völgyi / György Farkas / Salem G. Nehme
}

Received 2009-10-10, revised 2009-11-12, accepted 2009-12-10

\begin{abstract}
The aim of the research was to characterize the concrete mixtures for spun-cast concrete and to determine the relationship between the compacting ratio and the manner of segregation. In the research 23 specimens of 9 different mixtures with low $w / c$ ratio were tested. Investigated parameters included $w / c$, spinning speed, duration, and properties of the aggregate. The strength of the concrete in the outer, middle and inner region of the spun-cast element and of the vibrated cube was assessed by testing drilled cores. The optimal compacting energy caused by spinning was defined for different mixtures. Statistical regression functions depending on the parameters above were defined for the change of strength in the wall of the element.
\end{abstract}

\section{Keywords}

spun-cast concrete $\cdot$ strength $\cdot$ experimental test

\section{Acknowledgement}

The authors wish to express their gratitude to BVM Épelem LTD, SW Umwelttechnik Hungary LTD, Railone LTD for the research materials and for sponsoring the research. Thanks to the Department of Structural Materials and Engineering Geology for their assistance in the laboratory work. Special thanks to Mr András Eipl.

\section{István Völgyi}

Department of Structural Engineering, BME, Bertalan L. u. 2, Budapest, H1111, Hungary

e-mail: volgyi@vbt.bme.hu

\section{György Farkas}

Department of Structural Engineering, BME, Bertalan L. u. 2, Budapest, H1111, Hungary

e-mail: farkas@vbt.bme.hu

\section{Salem G. Nehme}

Department of Construction Materials and Engineering Materials, BME, Múegyetem rkp. 3. Budapest, H-1521, Hungary

e-mail: sgnehme@yahoo.com

\section{Notation}

c Consistence determined by flow table tests [cm]

$f_{\text {cm,cyl }}$ Mean value of compressive strength of standard $150 \times 300 \mathrm{~mm}$ cylinder $[\mathrm{MPa}]$

$f_{\mathrm{cm}, \text { core }}$ Mean value of standard $(150 * 300 \mathrm{~mm})$ cylinder compressive strength of $60 \mathrm{~mm}$ diameter drilled core [MPa]

$f_{\text {cm,out }}$ Modified standard cylinder compressive strength of drilled core from outer region $[\mathrm{MPa}]$

$f_{\mathrm{cm}, \text { in }}$ Modified standard cylinder compressive strength of drilled core from inner region [MPa]

$f_{\text {cm,vib }}$ Modified standard cylinder compressive strength of drilled core from vibrated compacted specimen [MPa]

$n$ Rotation of the form per minute [1/min]

$\omega$ Angular velocity of the form $[\mathrm{rad} / \mathrm{sec}]$

$r$ Radial distance from specimen's longitudinal axis [mm]

$r_{i}$ Inner radius of the specimen [mm]

$r / \min$ Maximal rotation of the form per minute [1/min]

$t_{s}$ Spinning time [min]

$A_{\text {spec }}$ Specific surface of the aggregate fraction above $4 \mathrm{~mm}$ $\left[\mathrm{mm}^{2} / \mathrm{mm}^{3}\right]$

$E_{\text {app }}$ Applied compacting energy [J]

$E_{\text {app }}^{*}$ Modified compacting energy $\left[\mathrm{m}^{2} / \mathrm{sec}\right]$ [enlarged]

$E_{\max }^{*}$ Maximal recommended modified compacting energy $\left[\mathrm{m}^{2} / \mathrm{sec}\right]$ [enlarged]

$E_{\text {need }}^{*}$ Required modified compacting energy $\left[\mathrm{m}^{2} / \mathrm{sec}\right]$ [enlarged]

$P_{e}$ Paste excess $\left[\mathrm{dm}^{3} / \mathrm{m}^{3}\right]$

$R$ Outer radius of specimen $[\mathrm{mm}]$

$T$ Total time of spinning [sec] 
$\Delta f_{\mathrm{cm}}$ Relative cylinder strength variation from outer to inner region [\%]

$\rho_{\text {out }}$ Density of the outer region $\left[\mathrm{t} / \mathrm{m}^{3}\right]$

$\rho_{\text {mid }}$ Density of the middle region $\left[\mathrm{t} / \mathrm{m}^{3}\right]$

$\rho_{\text {in }}$ Density of the inner region $\left[\mathrm{t} / \mathrm{m}^{3}\right]$

\section{Introduction}

Spun-cast concrete poles and piles are typical mass products in several countries. This several decades old technology has lots of advantages. Better protection of reinforcement against corrosion, improved freeze-thaw resistance and resistance against chemical attack.

Spun-casting is an economical method for producing concrete elements with long tradition. In the mid-20th century concrete mixtures were made using high water-cement $(w / c)$ ratios. Excess water left the mixture during centrifugation. This way the strength of spun-cast concrete was much higher than the strength of vibrated test cylinders.

Nowadays the w/c ratio of mixtures is much lower because of the use of superplasticisers. So the strength of both spun-cast and vibrated concrete has changed. Today water does not leave the mixtures. Correlations between the strength of the spuncast and vibrated elements determined decades ago are not valid today. Due to segregation, strength changes throughout the wall of the element. Standards do not have any special rules for the strength of spun cast concrete mixtures or for the quality control of these products.

Firms try to find new application fields and reduce the cost of production, transportation and installation [10]. Today even more spun-cast reinforced concrete columns are installed into high-rise buildings and other structures [4,9]. The new application field implies a change in the dominant loading type. The main load of poles is the bending moment. Elements used as piles or columns have to have considerable resistance against shear force [16]. Shear force can be caused, for example, by vehicle impact in parking houses or by earthquake; piles in the fundament of a high-rise building are forced by shear too. To be able to examine the resistance of the hollow cylindrical spun-cast concrete elements against shear we need to know the strength properties of the concrete in the wall of the spun-cast concrete elements. Results have been published by some research studies in this topic [5, 16]. Available literature on spun poles mainly focuses on developing analytical procedures and suitable design criteria under service conditions. Very limited published research exists on the concrete technology of spuncast poles [3].

Today the quality control of spun-cast concrete elements is based on testing cylinders or cubes compacted with vibration $[6-8]$. The properties of spun-cast concrete, first of all its strength, are different due to the difference of the compacting method. Published literature [10] indicates that the strength of spun-cast concrete is higher than that of a specimen compacted on a vibratory table. These results are from testing the whole hollow specimen with a compressive force [18]. But strength of the concrete in the wall of the element is not constant.

Spinning concrete at high speed may cause segregation and different porosities within the concrete, which leads to differential shrinkage and strength [13]. Previous research shows that a reduction of fines in the concrete mixture is necessary to minimize segregation of the coarse and fine aggregate components of the mixture during the spinning process. A low water-cement ratio is also required to achieve high strength [5].

However, a low water-cement ratio along with the reduction of fines results in harsh mixtures difficult to compact. Hence, the use of superplasticisers becomes necessary. Spinning speed and duration are also important. High speed leads to good compaction but also to the segregation of aggregates.

The aim of the research was to characterize the concrete mixtures for spun-cast concrete and to determine the relationship between the compacting ratio and the manner of segregation.

\section{Experimental Program}

The experimental program consisted of the production and testing of nine series of concrete element segments during a period of approximately 6 months. The materials and mixture parameters used for preparing the specimens are briefly described below.

The research consisted of normal strength mixtures made with low water-cement ratio and silicous aggregate.

The variables investigated in this test series included spinning speed, spinning duration, type of aggregate, type of cement, amount of cement, and water-cement ratio.

$200 \mathrm{~mm}$ long, $500 \mathrm{~mm}$ diameter segments and $150 \times 300 \mathrm{~mm}$ control cylinders were produced on the spinning machines of the companies for each mixture to examine compressive strength.

Forms for two identical specimens were filled in, and lifted onto the spinning machine. The individual spinning program for the specimen was run. During the spinning, consistence of the mixture was determined by flow table tests and standard control cylinders and cubes were produced. After compacting the forms were opened. One of the specimens was removed, the other was left in the form. Material samples were taken from the outer, middle and inner regions of the wall of the freshly compacted specimen. Immediately after determination of fresh density, the samples were washed and dried. The composition of the samples was determined. The other specimen was left in the form. 28 days later $60 \mathrm{~mm}$ diameter cores (height 85 $95 \mathrm{~mm}$ ) were drilled from the outer, middle and inner regions of the specimen and from the vibratory compacted etalon specimen. Four test cores were made from each group (Fig. 1] Fig. 2). The mean value of the compressive strength of the cores and of the etalon standard $150 \times 300 \mathrm{~mm}$ specimens was determined. The test was accomplished after EN12504-1 [6]. 440 destructive compression strength tests were made. 


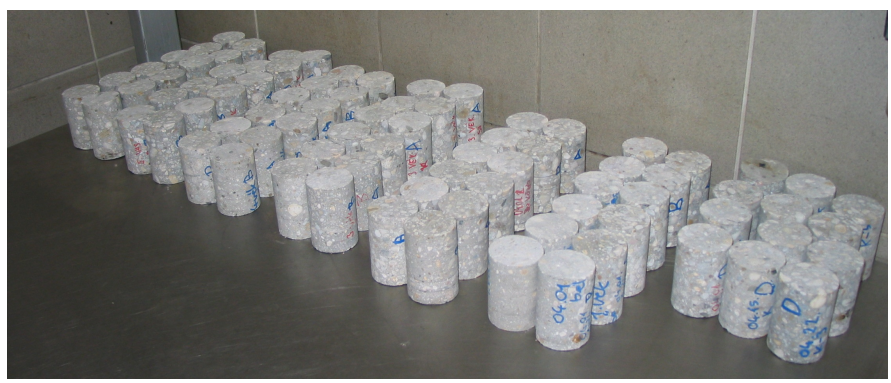

Fig. 1. Drilled cores from the specimens $\mathrm{A} / 1-\mathrm{C} / 4$

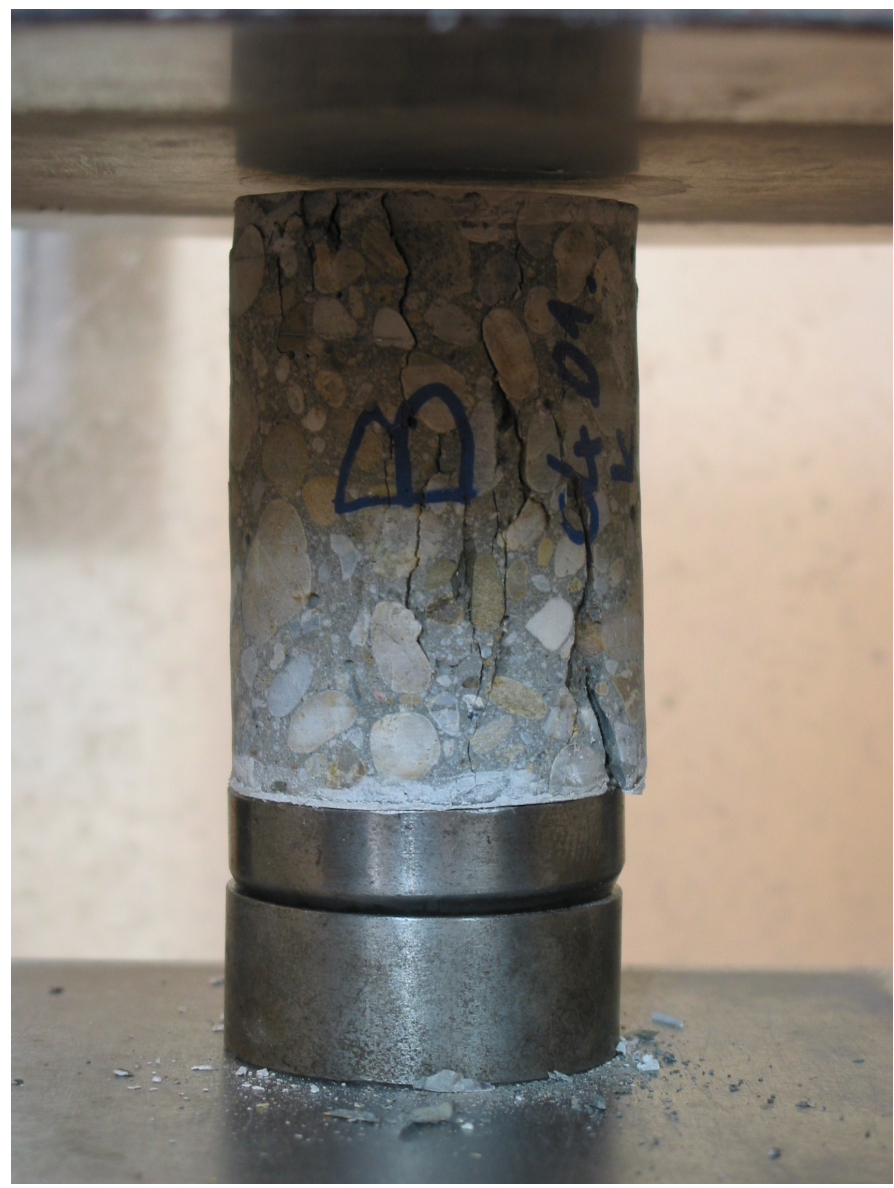

Fig. 2. Compressive test of $60 \mathrm{~mm}$ diameter drilled core

\section{Materials}

Real spun-cast concrete mixtures with siliceous aggregate and low water-cement ratio were modeled in the research. The usually used materials were applied for the mixtures. Rapid cement was applied for the mixtures, which is usual at precast structures. Every mixture in the research contained silicous aggregate. The grain size distribution of the aggregate structures was different. Three of the nine mixtures contained crushed gravel. Crushed gravel is also a typical aggregate type of spun-cast concrete elements. The mixtures contained river sand as fine aggregate. Limestone filler was added to one of them. This was an own formulation of the firm.

Superplasticiser admixtures were used to improve the natural finish of concrete. Different types of admixtures were used because of their secondary effects. Admixtures improve early age

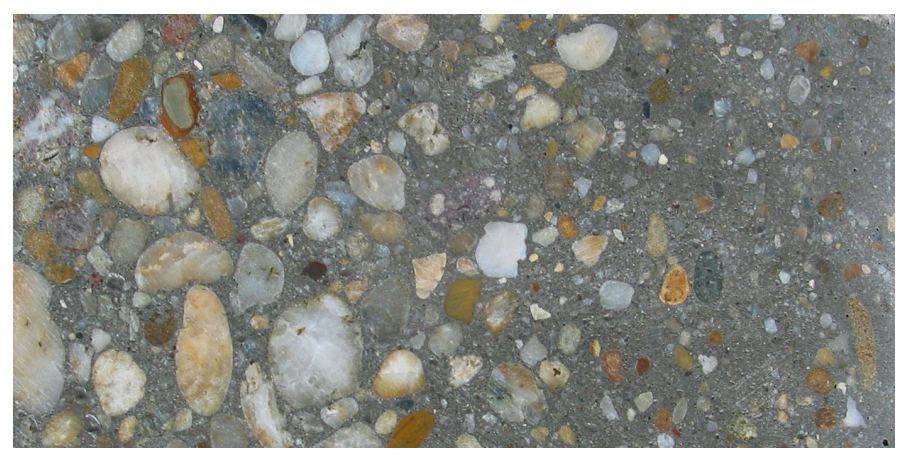

Fig. 3. Hard segregation in the wall of specimen $\mathrm{A} / 1$

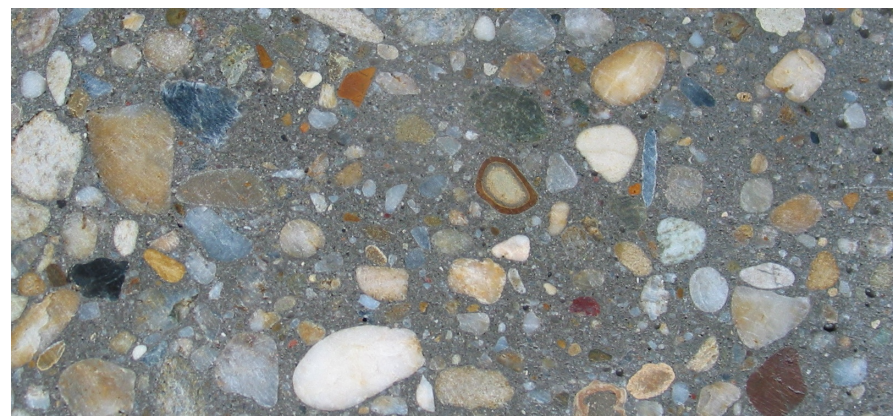

Fig. 4. Soft segregation in the wall of specimen $B / 3$

strength and avoid the segregation of mixture. The secondary effect of admixtures is the modification of slump retention. Mixtures named $F$ and $G$ were produced in the summer. A superplasticiser with the secondary effect of long slump retention was used for them. Table 1 shows the mixture parameters of the concrete series.

\section{Mixture parameters}

Spun-cast concrete poles and piles need to have relative high mechanical strength to be resistant to chemical effects. Mixtures need to be made with a low water-cement ratio.

The superplasticiser was added directly to the mixture after all the other ingredients (cement, aggregates, water). The minimum mixing time was 5 minutes.

The concrete mixtures were tested for their strength and suitability in producing spun-cast concrete. The mixtures in this series were divided into two main groups, namely: mixtures containing natural gravel aggregate and mixtures containing crushed gravel aggregate.

\section{Observation and test results}

Material samples were taken from the outer, middle and inner regions. After washing using a $0,25 \mathrm{~mm}$ sieve, the modified grain size distribution diagrams of the samples were created using the results measured. This is a very similar type of diagram to the standard grain size distribution diagram. The only difference is that the values shown represent the proportion of the whole weight of the mixture. Fig. 3 and Fig. 4 show the cross sections of specimens $\mathrm{A} / 1$ and $\mathrm{B} / 3$. 
Tab. 1. Mixture properties

\begin{tabular}{|c|c|c|c|c|c|c|c|c|c|c|c|}
\hline \multirow[t]{2}{*}{ Mixture } & \multirow{2}{*}{$\begin{array}{c}\text { Sand } \\
0-4\end{array}$} & \multicolumn{3}{|c|}{ Silicous gravel } & \multicolumn{2}{|c|}{$\begin{array}{c}\text { Crushed } \\
\text { gravel }\end{array}$} & \multirow[t]{2}{*}{ Cement type } & \multirow[t]{2}{*}{$\begin{array}{c}\text { Cement } \\
{[\mathrm{kg}]}\end{array}$} & \multirow[t]{2}{*}{$\begin{array}{c}\text { Water } \\
\text { [kg] }\end{array}$} & \multirow[t]{2}{*}{ Superplasticizer } & \multirow[t]{2}{*}{$\begin{array}{l}\text { Fineness } \\
\text { modulus }\end{array}$} \\
\hline & & $2-8$ & $4-8$ & $8-16$ & $0-5$ & $5-12$ & & & & & \\
\hline$A$ & $31,90 \%$ & $25,30 \%$ & & $42,80 \%$ & & & CEM I 42,5 R & 460 & 150 & Glenium C323 mix & 6,20 \\
\hline B & $34 \%$ & $25 \%$ & & $41 \%$ & & & CEM I 42,5 R & 420 & 143 & Glenium C323 mix & 6,35 \\
\hline $\mathrm{C}$ & $32 \%$ & $25 \%$ & & $43 \%$ & & & CEM I 42,5 R & 420 & 143 & Glenium C323 mix & 6,43 \\
\hline $\mathrm{D}$ & $19 \%$ & & & $32 \%$ & $24 \%$ & $25 \%$ & CEM I 52,5 N & 400 & 136 & Mapei Dynamon SP1 & 6,30 \\
\hline$E$ & $43 \%$ & & $30 \%$ & $27 \%$ & & & CEM I 52,5 N & 420 & 143 & Mapei Dynamon SP1 & 6,03 \\
\hline $\mathrm{F}$ & $40 \%$ & & $25 \%$ & $35 \%$ & & & CEM I 52,5 N & 420 & 143 & Mapei Dynamon SR3 & 6,55 \\
\hline $\mathrm{G}$ & $50 \%$ & & $10 \%$ & & & $40 \%$ & CEM I 52,5 N & 460 & 138 & Mapei Dynamon SR3 & 6,06 \\
\hline $\mathrm{H}$ & $67 \%$ & & & & & $33 \%$ & CEM I 52,5 N & 495 & 150 & Mapei Dynamon SP1 & 5,54 \\
\hline 1 & $45 \%$ & & $25 \%$ & $30 \%$ & & & CEM I 52,5 N & 495 & 150 & Stabiment FM 95E & 6,00 \\
\hline
\end{tabular}

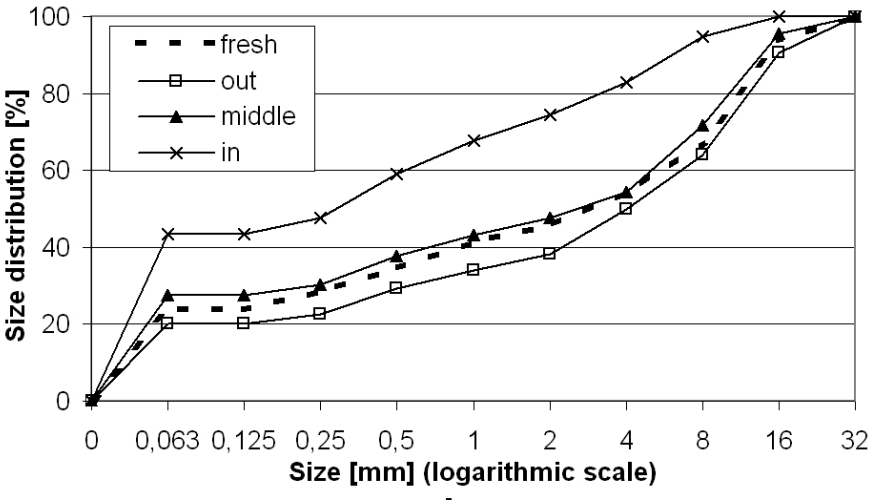

Fig. 5. Size distribution in material samples of specimen $\mathrm{A} / 1$

Figure 5 and Figure 6 show the distribution diagrams of the specimens shown in Figure 3 and Figure 4. The diagrams show the effect of different segregations on grain size distribution.

Fresh density of the removed material samples and of the vibratory compacted mixture were measured. Later on the dry density of drilled cores was measured, too. The data show the same tendency. Results from the cores were used for additional analysis because of the higher number of measurement data. Four drilled cores were taken from each region. A short summary of the results is shown in Table 2. Densities of the different regions and of the etalon specimens were compared. This way the specimens were divided into five classes. The classes and their definitions are listed below.

1 Spinning energy is not enough for the proper compacting of the mixture. The outer surface is not compact. The density of spun-cast specimen regions is lower than that of the vibratory compacted specimen.

2 Spinning energy is not enough for the proper compacting of the whole specimen. The outer surface is not compact enough. The average density of spun-cast specimen regions is not lower than that of the vibratory compacted specimen, but the density does not increase towards the outer region.

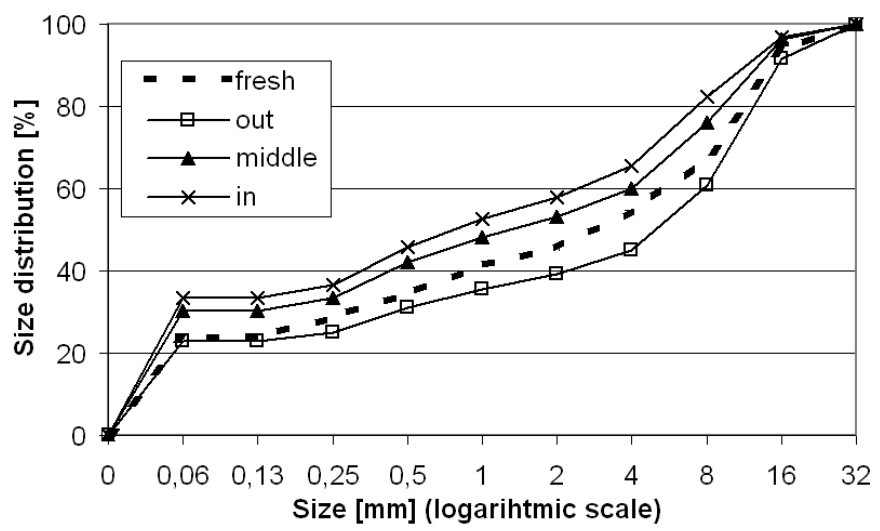

Fig. 6. Size distribution in material samples of specimen $B / 3$

3 The specimen is well compacted. The outer surface is compact. Average density of spun-cast specimen regions is higher than that of the vibratory compacted specimen. Density slightly increases from the inner to the outer region. See Fig. 4 and Fig. 6 .

4 The specimen is well compacted. The outer surface is compact. The average density of spun-cast specimen regions is higher than that of the vibratory compacted specimen. There is a significant density increment from the inner to the outer region caused by segregation.

5 There is a high density increment from the inner to the outer region caused by segregation. Hard segregation. Too much compacting energy. See Fig. 3 and Fig. 5

The compacting ratio depends on the required compacting energy of the mixture [17]. The compaction need apparently depends on the consistence of the mixture. Several literature studies are available on the energy need for the compacting of different mixtures [12,14]. But spun-casting is a special compacting method. The mixture pieces are moved by centrifugal pressure. Spun-casting and vibratory compacting are very different phenomena [2]. The spinning energy need of mixtures was deter- 
Tab. 2. Summary of parameters and results

\begin{tabular}{|c|c|c|c|c|c|c|c|c|c|c|c|c|c|c|c|}
\hline Name & $\rho_{\text {out }}$ & $f_{c m, o u t}$ & $f_{c m, m i d}$ & $f_{c m, i n}$ & $\frac{f_{\text {cm }, \text { out }}}{f_{\text {cm }, \text { out }}}$ & $\Delta f_{c m}$ & $\frac{\rho_{\text {out }}}{\rho_{\text {vib }}}$ & $C$ & $\mathrm{Pe}$ & $E_{\text {app }}^{*}$ & $\begin{array}{l}\text { Comp. } \\
\text { class }\end{array}$ & $\frac{E_{\text {app }}^{*}}{E_{\text {need }}^{*}}$ & $A_{\mathrm{spec}}$ & $\mathrm{r} / \mathrm{min}$ & $t_{s}$ \\
\hline $\mathrm{A} / 1$ & 2.49 & 47.2 & 49.4 & 65.8 & 0.80 & 0.31 & 1.04 & 38 & 100.8 & 30.9 & 5 & 2.93 & 80.3 & 310 & 12.0 \\
\hline $\mathrm{A} / 2$ & 2.48 & 49.4 & 53.5 & 60.7 & 0.83 & 0.19 & 1.03 & 38 & 100.8 & 27.7 & 4 & 2.63 & 80.3 & 310 & 12.0 \\
\hline $\mathrm{A} / 3$ & 2.44 & 53.1 & 54.3 & 56.4 & 0.89 & 0.06 & 1.02 & 38 & 100.8 & 13.4 & 3 & 1.27 & 80.3 & 193 & 12.0 \\
\hline $\mathrm{A} / 4$ & 2.45 & 53.0 & 55.9 & 53.8 & 0.89 & 0.01 & 1.02 & 38 & 100.8 & 12.0 & 3 & 1.14 & 80.3 & 193 & 12.0 \\
\hline $\mathrm{B} / 1$ & 2.46 & 51.3 & 56.2 & 61.6 & 0.94 & 0.19 & 1.04 & 30 & 104.9 & 21.2 & 3 & 1.18 & 80.7 & 294 & 10.5 \\
\hline $\mathrm{B} / 2$ & 2.44 & 54.5 & 57.4 & 61.6 & 1.00 & 0.08 & 1.04 & 30 & 104.9 & 19.7 & 3 & 1.10 & 80.7 & 294 & 10.5 \\
\hline $\mathrm{B} / 3$ & 2.42 & 52.1 & 54.9 & 57.5 & 0.95 & 0.10 & 1.03 & 30 & 104.9 & 16.4 & 3 & 0.91 & 80.7 & 235 & 10.5 \\
\hline $\mathrm{B} / 4$ & 2.46 & 49.3 & 55.3 & 62.2 & 0.90 & 0.23 & 1.04 & 30 & 104.9 & 15.1 & 3 & 0.84 & 80.7 & 235 & 10.5 \\
\hline $\mathrm{C} / 1$ & 2.48 & 53.5 & 58.5 & 62.0 & 0.96 & 0.15 & 1.03 & 28 & 100.2 & 21.0 & 3 & 0.93 & 80.1 & 294 & 10.5 \\
\hline $\mathrm{C} / 2$ & 2.48 & 54.0 & 63.6 & 62.5 & 0.97 & 0.15 & 1.03 & 28 & 100.2 & 19.9 & 3 & 0.88 & 80.1 & 294 & 10.5 \\
\hline $\mathrm{C} / 3$ & 2.48 & 56.0 & 61.2 & 64.3 & 1.01 & 0.15 & 1.03 & 27 & 100.2 & 33.3 & 3 & 1.25 & 80.1 & 356 & 11.5 \\
\hline $\mathrm{C} / 4$ & 2.49 & 54.0 & 57.3 & 60.8 & 0.97 & 0.12 & 1.03 & 27 & 100.2 & 30.8 & 3 & 1.16 & 80.1 & 356 & 11.5 \\
\hline $\mathrm{D} / 1$ & 2.43 & 58.5 & 65.5 & 70.8 & 0.90 & 0.19 & 1.01 & 24 & 75.2 & 45.2 & 1 & 0.65 & 114.2 & 360 & 11.5 \\
\hline $\mathrm{D} / 2$ & 2.49 & 68.9 & 69.1 & 71.9 & 1.06 & 0.05 & 1.04 & 25 & 75.2 & 60.3 & 3 & 1.40 & 114.2 & 498 & 9.0 \\
\hline$E / 1$ & 2.45 & 44.7 & 52.6 & 53.8 & 0.96 & 0.20 & 1.02 & 33 & 83.0 & 25.7 & 4 & 1.84 & 95.6 & 360 & 7.0 \\
\hline$E / 2$ & 2.43 & 45.6 & 48.7 & 50.7 & 0.98 & 0.11 & 1.01 & 33 & 83.0 & 17.2 & 4 & 1.23 & 95.6 & 304 & 6.5 \\
\hline $\mathrm{F} / 1$ & 2.45 & 57.0 & 58.9 & 61.1 & 1.01 & 0.07 & 1.02 & 26 & 89.4 & 52.4 & 3 & 1.62 & 88.7 & 415 & 10.5 \\
\hline $\mathrm{F} / 2$ & 2.35 & 42.5 & 44.5 & 47.6 & 0.75 & 0.09 & 0.98 & 24 & 89.4 & 35.9 & 1 & 0.51 & 88.7 & 387 & 8.5 \\
\hline $\mathrm{G} / 1$ & 2.37 & 58.2 & 63.5 & 64.4 & 1.01 & 0.11 & 0.99 & 25 & 76.6 & 56.2 & 2 & 1.31 & 145.5 & 415 & 10.5 \\
\hline $\mathrm{G} / 2$ & 2.34 & 47.6 & 50.7 & 52.8 & 0.83 & 0.09 & 0.98 & 24 & 76.6 & 57.1 & 1 & 0.82 & 145.5 & 443 & 9.5 \\
\hline $\mathrm{H} / 1$ & 2.40 & 39.4 & 30.8 & 28.5 & 0.78 & 0.30 & 1.00 & 30 & 88.1 & 61.8 & 5 & 3.45 & 150.6 & 498 & 8.0 \\
\hline $\mathrm{I} / 1$ & 2.47 & 59.8 & 68.4 & 62.8 & 0.82 & 0.26 & 1.03 & 43 & 114.7 & 22.4 & 4 & 2.60 & 91.1 & 240 & 12.0 \\
\hline $\mathrm{I} / 2$ & 2.46 & 65.8 & 64.3 & 64.3 & 0.84 & 0.24 & 1.01 & 41 & 114.7 & 22.5 & 4 & 2.43 & 91.1 & 240 & 12.0 \\
\hline
\end{tabular}




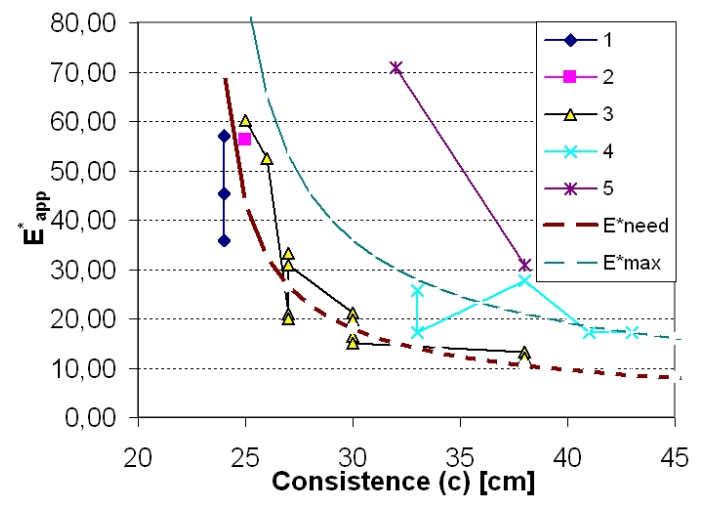

Fig. 7. Recommended minimum and maximum compacting energy to the consistence of mixture; class 1: deficient compaction, class 2 : partly deficient compaction, class 3: well compacted specimen, class 4: significant segregation caused by over-compaction, class 5: hard segregation, too much compacting energy

mined using defined classes of specimens. Figure 7 shows the five groups of the specimens. The enabled applied compacting energy was plotted as a function of consistence of the mixture. The enlarged applied compacting energy was calculated using eq. (1). Equation (1) is a summation of the centripetal pressure on the wall of the form using a fluid material model [16].

$$
E_{\text {app }}=\int_{0}^{T} \int_{r_{i}}^{R} \rho \cdot r \cdot \omega^{2} \cdot \frac{r}{R} d r d t
$$

In a modified expression, equation (2) is shown after reducing equation (1).

$$
E_{\mathrm{app}}^{*}=\int_{0}^{T} \int_{r_{i}}^{R} r \cdot n^{2} \cdot \frac{r}{R} d r d t \cdot 10^{-9}
$$

The results show a clear tendency. A power function was created to determine the required compacting energy (eq. (3) ) and the maximum recommended compacting energy (eq. (4)). The acceptance region of the formula is at a consistence of 25 to $40 \mathrm{~cm}$. Functions are able to separate the three main groups of specimens, namely undercompacted, normally compacted and overcompacted specimens.

$$
\begin{aligned}
& E_{\text {need }}^{*}=70 \cdot(c-23)^{0,7} \\
& E_{\text {max }}^{*}=140 \cdot(c-23)^{0,7}
\end{aligned}
$$

This function enabled us to use the compacting ratio $\left(E_{\text {app }}^{*} / E_{\text {need }}^{*}\right)$ as a parameter of strength variation in the wall.

The literature indicates that segregation significantly depends on the paste excess of the mixture [1]. Paste excess of the mixtures was calculated after Ujhelyi's method [15]. Paste excess is the second main parameter. Paste excess includes the concrete technological parameters amount of cement, water-cement ratio and fineness modulus of aggregate.
There are three main compressive failure modes of concrete. Low strength specimens fail in cement paste. The failure surface of high strength concrete specimens runs through the aggregate. In the average strength range, specimens fail at the interface of the aggregate and the cement paste. The specimens analyzed are in the third range. In our hypothesis, the specific area of the gravel fraction could affect the strength of the gravel-rich outer region. That is why crushed gravel was chosen for three mixtures. The specific area of crushed gravel is significantly higher than that of natural gravel. The specific area of the $>4 \mathrm{~mm}$ gravel fraction of the mixtures was determined using Kausay's method [11]. The specific area was the third parameter in the study.

The strength values of the spun-cast concrete elements are normalized with the strength of the vibratory compacted specimens' strength. It is assumed that the effect of further parameters listed listed in chapter 3 on the spun-cast-vibratory strength ratio is not significant. Our results show, that standard deviation of strength of the separated regions of the spun cast concrete is lower than that of the vibrated specimens. The best physical value to describe an effect is the mean value. That is why mean value of the compressive strength of the specimens was used for the statistical analysis.

A statistical model was used to determine the strength properties of the spun-cast specimens depending on the parameters above. It is assumed that the strength variation in the wall is approximately linear. The specimens' compressive strength can also be characterized using two variables, namely the strength of the outer region and strength increment from the outer to the inner region.

A polynomial linear regression model was created to determine how the compressive strength of the outer region depends on paste excess, compacting ratio and aggregate surface. The result of the variance-covariance analysis shows that the result does not depend on paste excess and aggregate surface at $95 \%$ significance level. The best polynomial regression function is Eq. (5).

$$
\begin{aligned}
\frac{f_{\mathrm{cm}, \text { out }}}{f_{\mathrm{cm}, \mathrm{vib}}}= & 42,6+88,5 \cdot \frac{E_{\mathrm{app}}^{*}}{E_{\text {need }}^{*}}-39,5 \cdot\left(\frac{E_{\mathrm{app}}^{*}}{E_{\text {need }}^{*}}\right)^{2} \\
& +3,15 \cdot\left(\frac{E_{\text {app }}^{*}}{E_{\text {need }}^{*}}\right)^{3}+0,525 \cdot\left(\frac{E_{\mathrm{app}}^{*}}{E_{\text {need }}^{*}}\right)^{4} \\
& 0,5<\frac{E_{\text {app }}^{*}}{E_{\text {need }}^{*}}<3
\end{aligned}
$$

The residual variance of the regression function is $4 \%$. The function has a good correlation with the theory that optimal compacting energy causes high compacting level and low segregation. This causes high strength in the outer region (Fig. 8). Lower applied energy causes lower compacting level and of course lower strength. Too high compacting level causes extreme segregation and lower strength. 


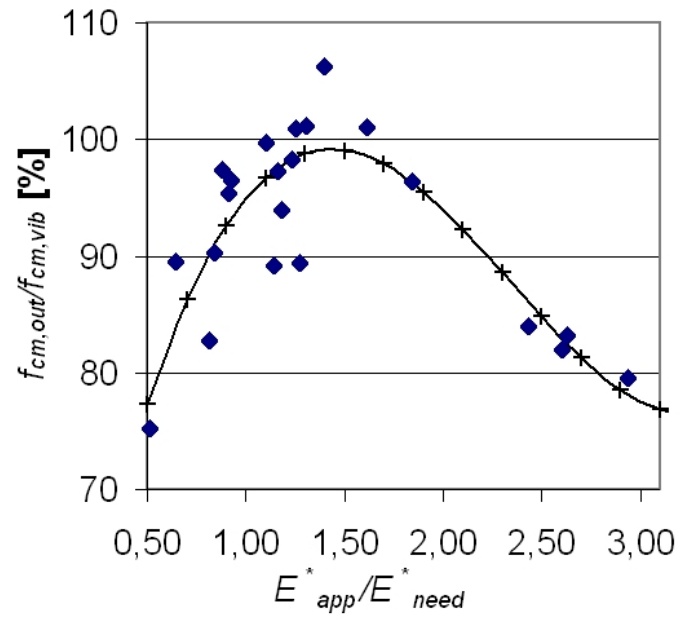

Fig. 8. Measured relative compressive strength of the outer region vs. relative compaction energy and values of the regression function vs. relative compaction energy

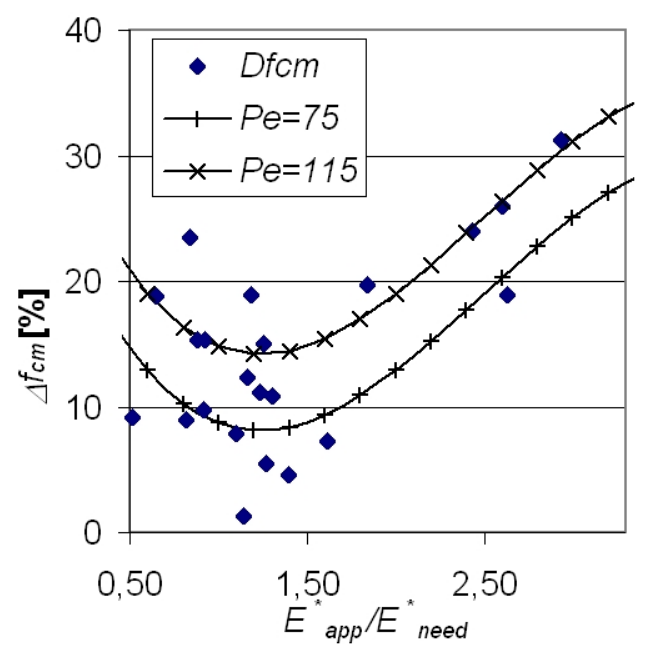

Fig. 9. Measured relative compressive strength variation in the wall of the element vs. relative compaction energy and values of the regression function vs. relative compaction energy (2D section)

The same method was used to determine how the compressive strength variation from the outer region to the inner region depends on paste excess, compacting ratio and aggregate surface (Figure 9). The result of the variance-covariance analysis shows that the result does not depend on aggregate surface at 95\% significance level. The best polynomial regression function is Eq. 66.

$$
\begin{aligned}
\Delta f_{c m}= & 21,1+0,11 \cdot P_{e}-37,7 \cdot \frac{E_{\text {app }}^{*}}{E_{\text {need }}^{*}}+20,3 \cdot\left(\frac{E_{\text {app }}^{*}}{E_{\text {need }}^{*}}\right)^{2} \\
& -2,73 \cdot\left(\frac{E_{\text {app }}^{*}}{E_{\text {need }}^{*}}\right)^{3} \\
& 0,5<\frac{E_{\text {app }}^{*}}{E_{\text {need }}^{*}}<3 \quad 75 \frac{d m^{3}}{m^{3}}<P_{e}<110 \frac{d m^{3}}{m^{3}}
\end{aligned}
$$

\section{Conclusions}

Conclusions for the mixtures of the research are as follows.
Segregation of concrete mixture during spun-casting depends significantly on paste excess and on the compacting ratio. Mixture segregation can be significantly reduced by using mixture with lower paste excess and optimal compacting energy.

The inner-side strength of a well compacted specimen is always higher than that of a vibratory compacted specimen. Its outer-side strength is usually lower than that of the vibratory compacted specimen. Lower segregation causes lower strength variation in the wall of the elements.

The relationship between consistence and modified compaction energy need was determined. This expression is able to calculate optimal spinning machine settings for the best strength properties of the specimen.

Using a statistical regression model, a polynomial function was determined for the compressive strength of the outer region of spun-cast concrete elements as a function of the compacting ratio. The relative compressive strength of the outer region does not significantly depend on paste excess and aggregate surface.

Using a statistical regression model, a polynomial function was determined for the variation of compressive strength from the outer region to the inner region of spun-cast concrete elements as a function of the compacting ratio and paste excess. The relative compressive strength of the outer region does not significantly depend on aggregate surface.

The functions are able to help in optimizing the production of spun-cast concrete elements. The functions can be used for determining the strength of elements whose wall thickness is not sufficient for drilling $60 \mathrm{~mm}$ diameter cores from the three regions.

\section{References}

1 Balázs Gy, Borján J, Horváth A, Schwerteczky F, Effect of inhomogenity on strength and deformation characteristics of concrete, Periodica Politechnica Civil Engineering 37 (1993), no. 4, 313-320.

2 Csutor J, Compacting of concrete (A beton tömörítése), Múegyetemi Kiadó, Budapest, 1967.

3 Dilger WH, Ghali A, Rao SV, Improving the durability and performance of Spun-Cast Concrete Poles, PCI Journal (1996), 68-89.

4 Dilger WH, Ghali A, Response of Spun Cast Concrete Poles to Vehicle Impact, PCI Journal (1986), 62-82.

5 Dilger WH, Rao SV, High Performance Concrete Mixtures for Spun-Cast Concrete Poles, PCI Journal (1997), 82-95.

6 EN 12504-1 - 2001 Testing concrete in structures. European standard.

7 EN 12843 - 2005 Precast concrete products. Masts and poles. European standard.

8 EN 13791-2007 Assessment of in-situ compressive strength in structures and precast concrete components. European standard.

9 Kudrys A, Kliukas R, The resistance of compressed spun-cast concrete members reinforced by high-strength steel bars, Materials and Structures $\mathbf{4 1}$ (2008), 419-430.

10 Beluzsár J, Beluzsár L, Sziklai Z, Construction and application of spun-cast concrete columns (Pörgetett vasbeton oszlopok gyártása és alkalmazása), 2006. www.mabesz.org.

11 Kausay T, Composition properties of concrete aggregates and complex characterization of composition (Betonadalékanyagok szemszerkezeti tulajdon- 
ságai és a szemszerkezet komplex jellemzésmódja), Budapest University of Technology and Economics, 1976.

12 Kausay T, Szirmai A, Measuring Consistence in mixing machines (Konzisztenciamérés betonkeverógépekben), Építőanyag XXXI (1979), no. 5, 170178.

13 Nehme SG, Balázs LGy, Effect of porosity on the properties of concrete, Concrete Structures (2003), no. 4, 72-75.

14 Rácz K, Arany P, Pristyák A, Examination of relationship of Cube strength and vibration compacting parameters, Budapest University of Technology and Economics, 1977.

15 Ujhelyi J, Concrete sciences, (Betonismeretek), Múegyetemi Kiadó, Budapest, 2005.

16 Völgyi I, Farkas Gy, Concrete technologial and structural problems of spun-cast concrete elements, ÉPKO 2009, 2009, pp. 501-506.

17 _ Determination of strength of spun-cast concrete elements, Fifth International PhD DLA Symposium, 2009, pp. 70-71.

18 Yuanhai J, Shun J, Tubular pile centrifugal high strength concrete compression strength testing method by drill core, 2003. ChemYQ. 